\title{
Clohesyomyces symbioticus sp. nov., a fungal endophyte associated with roots of water smartweed (Persicaria amphibia)
}

\author{
A. Elizabeth Arnold ${ }^{1,2^{*}}$ \& Dustin C. Sandberg ${ }^{1}$
}

\section{Article info}

Received: 17 Sept. 2021

Revision received: 8 Dec. 2021

Accepted: 11 Dec. 2021

Published: 31 Dec. 2021

Associate Editor

Marcin Piątek

\begin{abstract}
The widespread aquatic plant Persicaria amphibia (water smartweed, Polygonaceae) occurs in both flooded aquatic habitats and moist terrestrial environments. Its physiological versatility and wide geographic range highlight its resilience to stress and make the species intriguing for the study of fungal endophytes. Endophytes occur within living plant tissues and are known from diverse aquatic, marine, and terrestrial plants, where they often mitigate plant responses to stress. As part of a study evaluating endophyte communities associated with aquatic plants in lentic waters of Arizona, USA, we isolated a distinctive clade of endophytes from healthy, living roots of seasonally inundated $P$. amphibia, which we describe here on the basis of morphology and evidence from four loci as new species Clohesyomyces symbioticus (Lindgomycetaceae, Pleosporales, Dothideomycetes, Ascomycota). Clohesyomyces has long been considered a monotypic genus comprising the saprobic species $C$. aquaticus, presently known from submerged wood in freshwater systems in Asia and Australia. Description of Clohesyomyces symbioticus highlights the occurrence of endophytism in this genus and expands its geographic scope to the western hemisphere.
\end{abstract}

Key words: Endophytic, freshwater, Hongkongmyces, Lindgomyces, macrophyte, Polygonum, symbiosis

\section{Introduction}

Aquatic plants that persist under non-inundated conditions often have physiology and root traits that may attract distinctive fungal symbionts relative to purely aquatic and purely terrestrial plants (Sandberg et al. 2014; Moora et al. 2016; Stevens et al. 2018). Although it is primarily aquatic, water smartweed (Persicaria amphibia, Polygonaceae) is an emergent macrophyte that can survive in moist locations or when stranded by receding waters (Mitchell 1968; Costea 2012). It typically is found in shallow, still water in ponds and lakes, along the margins of rivers and streams, and in moist locations such as meadows (Flora of North America, www.efloras.org). Water smartweed has a wide geographic range, occurring natively in Europe, Asia, North America, and northern Africa (USDA-ARS GRIN-Global, https://npgsweb.arsgrin.gov) and as an introduced species in Mexico, southern Africa, and South America (Partridge 2001). In the United States, it is recorded in at least 46 states (Flora

\footnotetext{
${ }^{1}$ School of Plant Sciences, University of Arizona, Department of Ecology and Evolutionary Biology, University of Arizona, USA

21140 E South Campus Drive, Forbes 303, The University of Arizona, Tucson, AZ 85721 USA

Arnold, ORCID: 0000-0002-7013-4026

* Corresponding author e-mail: arnold@ag.arizona.edu
}

of North America, www.efloras.org), including Arizona, where it occurs in natural and impounded waters.

We previously characterized communities of fungal symbionts associated with leaves and roots of $P$. amphibia in lentic systems in central Arizona, with a special focus on fungal endophytes (Sandberg et al. 2014). Fungal endophytes (hereafter, endophytes) occur within living tissues without causing symptoms of disease (Rodriguez et al. 2009). Endophytes of aquatic plants are often highly diverse and distinctive relative to the endophyte communities found in plants in nearby terrestrial environments (e.g., Kohout et al. 2012; Sandberg et al. 2014; You et al. 2015; Duan et al. 2019).

As part of our surveys, we detected a distinctive group of isolates with unusual greyish and olivaceous growth. Sequence data from the internal transcribed spacers and 5.8S gene (ITS rDNA) suggested an affiliation with Lindgomycetaceae (Hirayama et al. 2010), but no strong affiliation with any previously described species. Here we characterize three representative strains based on morphology and molecular analyses as a new species of Clohesyomyces. The genus was previously considered monotypic, with C. aquaticus described as a saprobe that lives on submerged wood in Asia and Australia (Hyde 1993; Zhang et al. 2012). Our study 
highlights the large geographic range of Clohesyomyces, now including southwestern North America, and expands the ecological scope of the genus by including endophytism in living roots.

\section{Materials and methods}

Focal strains (DM0144, DM0177 and DM0192) were isolated from surface-sterilized, submerged, healthy roots of Persicaria amphibia (syn. Polygonum amphibium) collected in June 2012 at Willow Creek Reservoir (also known as Willow Lake) in Prescott, Yavapai County, Arizona, USA (34.602067, -112.437950). Roots were collected by gently digging up healthy plants in shallow water in areas of the reservoir separated by about $30-40 \mathrm{~m}$ from one another. Collection details were presented in Sandberg et al. (2014).

Plant tissues were washed and surface-sterilized as described by Sandberg et al. (2014) prior to plating on $2 \%$ malt extract agar (MEA) under sterile conditions. Axenic isolates were preserved as living vouchers in sterile water at room temperature prior to subsequent characterization.

\section{Culturing and assays}

Isolates were regrown from vouchers by transferring small hyphal plugs to $2 \%$ MEA supplemented with $50 \mu \mathrm{g} / \mathrm{mL}$ kanamycin sulfate, $40 \mu \mathrm{g} / \mathrm{mL}$ ciprofloxacin, $100 \mu \mathrm{g} / \mathrm{mL}$ ampicillin salt, and $15 \mu \mathrm{g} / \mathrm{mL}$ tetracycline $\mathrm{HCl}$ (see Hoffman and Arnold 2010). These plates were used to provide fresh mycelia for culturing, assays, and molecular analyses, per below.

A plug of actively growing mycelium was transferred from each isolate to $2 \%$ MEA in a $60 \mathrm{~mm}$ Petri dish. After $\sim 10$ days of growth at $\sim 22^{\circ} \mathrm{C}$ with natural light/ dark cycles, each isolate was transferred under sterile conditions to $100 \mathrm{~mm}$ Petri dishes containing either 2\% MEA, potato dextrose agar (PDA), water agar, water agar amended with thrice autoclaved pine needles (Harrington et al. 2019), cellulose medium (Gazis et al. 2012), or lignin (indulin) medium (Gazis et al. 2012). The plates were incubated under the above laboratory conditions for $14 \mathrm{~d}$. Growth of each isolate on each medium was characterized and cellulase and ligninase assays were performed as in Gazis et al. (2012).

Microscopy was conducted following Harrington et al. (2019) with images captured on Leica DM4000b and Nikon Eclipse $\mathrm{Ni}$ compound microscopes and a Nikon SMZ18 dissecting microscope with stacking and adjustment in Helicon Focus 7. We compared morphology with records for representative Lindgomycetaceae as published by Hyde (1993) (original description of the genus Clohesyomyces and the type species, C. aquaticus), as well as Hirayama et al. (2010), Raja et al. (2011, 2013, 2015, 2017), Raudabaugh et al. (2018), and Zhang et al. (2012).

\section{Molecular analyses}

Total genomic DNA was extracted from each isolate with the Sigma RedExtract-n-Amp plant PCR kit (Sigma-Aldrich, St. Louis, MO, USA) per the manufacturer's protocol. The following primers were used to amplify ITS rDNA, the nuclear ribosomal small subunit (SSU rDNA), the nuclear ribosomal large subunit (LSU rDNA) and translation elongation factor 1 alpha $(T E F-1 a)$ : ITS rDNA: ITS1F, ITS5, ITS4; LSU rDNA: LROR, LR3, LR7; SSU rDNA: NS1, NS4; TEF-1a: EF1-983F, EF12281R (Vilgalys \& Hester 1990; White et al. 1990; Gardes \& Bruns 1993; Hopple \& Vilgalys 1994; Carbone and Kohn 1999; Rehner \& Buckley 2005).

The PCR reaction mixture for each nuclear ribosomal region consisted of $10 \mu \mathrm{l}$ of REDExtract-N-Amp PCR Ready Mix, $0.8 \mu \mathrm{l}$ of each primer, $7.9 \mu \mathrm{l}$ of molecular grade water, and $0.65 \mu$ l of total genomic DNA template. The reaction mixture for TEF-1a consisted of $10 \mathrm{ul}$ of DreamTaq Hot Start Green Master Mix (Thermo Scientific, Waltham, MA, USA), $0.8 \mu \mathrm{l}$ of each primer, $6.9 \mu \mathrm{l}$ of molecular grade water, and $2 \mu \mathrm{l}$ of total genomic DNA template. When amplification did not occur for TEF-1a with the EF1-983F/EF1-2218R primer set, products from the initial first round of amplification were diluted 1:10 with molecular grade water and used as the template for a second PCR under the same reaction and cycle conditions as the first round. We used negative controls in all PCRs. All amplifications were performed in a MJ Research PTC200 thermocycler (Waltham, MA). Cycle conditions for each region are given in Table 1.

After visualization on a $1 \%$ agarose gel, PCR products were cleaned with ExoSAP-IT (Thermo-Fisher, Waltham, MA) and sequenced at the University of Arizona Genetics core (bidirectional Sanger sequencing with the primers used in PCR). The software applications phred and phrap (http://phrap.org) were used to call bases and assemble contigs with automation provided by the ChromaSeq package in Mesquite v. 1.06 (http://mesquiteproject.org). Base calls were checked by eye against chromatograms in Sequencher v. 4.5 (Gene Codes, Anne Arbor, MI).

\section{Phylogenetic analyses}

Comparison of ITS rDNA sequences with GenBank records via BLAST revealed top matches for the focal strains in the Lindgomycetaceae, a family of primarily

Table 1. PCR conditions following Arnold et al. (2009) and Harrington et al. (2019).

\begin{tabular}{|c|c|c|c|c|c|c|}
\hline Gene & Initial denature & Denature & Anneal & Extend & Cycles & Final extension \\
\hline ITS rDNA & $94^{\circ} \mathrm{C} / 3 \mathrm{~min}$ & $94^{\circ} \mathrm{C} / 30 \mathrm{sec}$ & $54^{\circ} \mathrm{C} / 30 \mathrm{sec}$ & $72^{\circ} \mathrm{C} / 1 \mathrm{~min}$ & 34 & $72^{\circ} \mathrm{C} / 10 \mathrm{~min}$ \\
\hline LSU rDNA & $94^{\circ} \mathrm{C} / 3 \mathrm{~min}$ & $94^{\circ} \mathrm{C} / 30 \mathrm{sec}$ & $50^{\circ} \mathrm{C} / 1 \mathrm{~min}$ & $72^{\circ} \mathrm{C} / 1 \mathrm{~min}$ & 34 & $72^{\circ} \mathrm{C} / 10 \mathrm{~min}$ \\
\hline SSU rDNA & $94^{\circ} \mathrm{C} / 3 \mathrm{~min}$ & $94^{\circ} \mathrm{C} / 1 \mathrm{~min}$ & $51^{\circ} \mathrm{C} / 30 \mathrm{sec}$ & $72^{\circ} \mathrm{C} / 1 \mathrm{~min}$ & 34 & $72^{\circ} \mathrm{C} / 10 \mathrm{~min}$ \\
\hline$T E F-1 a$ & $95^{\circ} \mathrm{C} / 5 \mathrm{~min}$ & $95^{\circ} \mathrm{C} / 1: 30 \mathrm{~min}$ & $55^{\circ} \mathrm{C} / 90 \mathrm{sec}$ & $72^{\circ} \mathrm{C} / 1 \mathrm{~min}$ & 35 & $72^{\circ} \mathrm{C} / 10 \mathrm{~min}$ \\
\hline
\end{tabular}


Table 2. Growth of focal strains on 2\% MEA. Color codes follow Kornerup \& Wanschen (1967).

\begin{tabular}{|c|c|c|c|c|c|c|c|c|c|}
\hline & $\begin{array}{l}\text { Diameter at } \\
14 \mathrm{~d}(\mathrm{~mm})\end{array}$ & $\begin{array}{l}\text { Color, } \\
\text { above: Cen- } \\
\text { tral colony }\end{array}$ & $\begin{array}{c}\text { Color, } \\
\text { above: } \\
\text { Colony edge }\end{array}$ & $\begin{array}{c}\text { Growth visible } \\
\text { as rings from } \\
\text { above }\end{array}$ & $\begin{array}{l}\text { Colony } \\
\text { texture }\end{array}$ & $\begin{array}{l}\text { Color, } \\
\text { below: Cen- } \\
\text { tral colony }\end{array}$ & $\begin{array}{c}\text { Color, } \\
\text { below: } \\
\text { Colony edge }\end{array}$ & $\begin{array}{l}\text { Growth } \\
\text { visible as } \\
\text { rings from } \\
\text { below }\end{array}$ & $\begin{array}{l}\text { Medium color, } \\
\text { after } 14 \mathrm{~d}\end{array}$ \\
\hline DM0144 & 39 & $3 \mathrm{E} 2$ & $3 \mathrm{E} 3$ & Yes & $\begin{array}{l}\text { Dense, } \\
\text { velvety }\end{array}$ & $3 \mathrm{~F} 2$ & $3 \mathrm{D} 2$ & No & Natural \\
\hline DM0177 & 34 & $3 \mathrm{E} 2$ & $3 \mathrm{C} 2$ & Yes & $\begin{array}{l}\text { Dense, } \\
\text { velvety }\end{array}$ & $3 \mathrm{~F} 2$ & $3 \mathrm{C} 2$ & No & $\begin{array}{l}\text { Mild reddish } \\
\text { pigment }\end{array}$ \\
\hline DM0192 & 39 & $3 \mathrm{~B} 1$ & $3 \mathrm{C} 2$ & Yes & $\begin{array}{l}\text { Dense, } \\
\text { velvety }\end{array}$ & $8 \mathrm{E} 4$ & $8 \mathrm{C} 2$ & No & $\begin{array}{l}\text { Diffuse, dark } \\
\text { red pigment }\end{array}$ \\
\hline
\end{tabular}

aquatic, wood-decaying fungi. Top matches included Hongkongmyces, Lindgomyces, and Clohesyomyces, including unidentified strains within these genera or affiliated with them. Based on Hirayama et al. (2010), Hyde et al. (2013), Raudabaugh et al. (2018), Raja et al. (2011, 2013, 2015, 2017), Tsang et al. (2014), and Zhang et al. (2012, 2014), as well as scrutiny of available sequence data in GenBank, and preliminary analyses designed to confirm outgroup taxa and clarify sequence quality, we generated the following alignments: (1) to confirm placement in Lindgomycetaceae, SSU rDNA (with Aquasubmersa and Didymosphaeria as outgroup taxa per Zhang et al. 2012) and LSU rDNA (with outgroups as above); and (2) to confirm placement in Clohesyomyces and confirm species placement, ITS rDNA and TEF-1a. Each dataset was aligned in MUSCLE (Edgar 2004) and verified by eye. Alignments are deposited at TreeBASE (study number 28770).

Each dataset was analyzed via maximum likelihood (ML) and maximum parsimony in GARLI (Zwickl 2006) and PAUP* 4.0a169 (Swofford 2003; https://paup.phylosolutions.com), respectively, as described in Harrington et al. (2019). For ML analyses, we used PAUP* 4.0a169 for automated model selection based on the Akaike Information Criterion, implementing GTR $+\mathrm{I}+$ gamma for SSU rDNA, LSU rDNA, and ITS rDNA and TIM + I for $T E F-1 a$. Topological support was evaluated with 1000 bootstrap replicates per Harrington et al. (2019).

\section{Results}

The focal strains grew readily under laboratory conditions on water agar, water agar amended with autoclaved pine needles, 2\% MEA, PDA, cellulose medium, and lignin medium. Details of growth on MEA and PDA are given in Table 2 and Table 3, respectively.
Analyses of the SSU rDNA and LSU rDNA placed the strains within Lindgomycetaceae with strong support (Fig. 1, Fig. 2). Analyses of ITS rDNA and TEF-1a confirmed placement within Clohesyomyces with strong support, and highlighted the distinctiveness of the focal isolates from C. aquaticus and other not-yet-named strains collected previously from Europe (Fig. 3, Fig. 4).

On MEA and PDA, gross colony morphology (Fig. 5, Fig. 6) was broadly consistent with that of $C$. aquaticus (Hyde 1993; Zhang et al. 2012), including the generally velvety to woolly, grey to greyish white to olivaceous appearance. Growth of the strains on MEA and PDA was relatively fast, with colony diameters of 34-39 mm and $44 \mathrm{~mm}$ after $14 \mathrm{~d}$, respectively (Table 2, Table 3 ). In comparison, Zhang et al. (2012) reported that C. aquaticus reached a colony diameter of $30 \mathrm{~mm}$ after $25 \mathrm{~d}$ at $25^{\circ} \mathrm{C}$, referring to it as slow-growing. However, Hyde (1993) reported a colony diameter of $90 \mathrm{~mm}$ in $7 \mathrm{~d}$ on PDA. Thus, growth rate of the type species of Clohesyomyces appears to be variable.

Hyde (1993) noted that C. aquaticus did not color PDA, but we observed reddish pigments from DM0177 and especially DM0192 on MEA and PDA (Tables 2, 3; Fig. 6). We also noted marked variation in colony appearance among the focal strains and observed that individual strains, when subcultured, could appear quite distinct from their source culture for at least several weeks, even on the same medium.

Hyde (1993) reported that $C$. aquaticus produced large numbers of conidiomata after $7 \mathrm{~d}$ on PDA. However, we only observed pycnidia development in the focal strains on water agar with pine needles (rarely on the pine needles themselves) and, after four weeks, on cut edges of MEA where material had been removed for subculturing (Fig. 5).

Table 3. Growth of focal strains on PDA. Color codes follow Kornerup \& Wanschen (1967).

\begin{tabular}{|c|c|c|c|c|c|c|c|c|c|}
\hline & $\begin{array}{l}\text { Diameter } \\
\text { at } 14 \mathrm{~d} \\
(\mathrm{~mm})\end{array}$ & $\begin{array}{l}\text { Color, above: } \\
\text { Central } \\
\text { colony }\end{array}$ & $\begin{array}{c}\text { Color, } \\
\text { above: } \\
\text { Colony edge }\end{array}$ & $\begin{array}{c}\text { Growth visible } \\
\text { as rings from } \\
\text { above }\end{array}$ & $\begin{array}{l}\text { Colony } \\
\text { texture }\end{array}$ & $\begin{array}{l}\text { Color, below: } \\
\text { Central } \\
\text { colony }\end{array}$ & $\begin{array}{c}\text { Color, } \\
\text { below: } \\
\text { Colony edge }\end{array}$ & $\begin{array}{l}\text { Growth visible } \\
\text { as rings from } \\
\text { below }\end{array}$ & $\begin{array}{c}\text { Medium } \\
\text { color, after } \\
14 \mathrm{~d}\end{array}$ \\
\hline DM0144 & 44 & 1B1 & 1B2 & No & $\begin{array}{l}\text { Dense, } \\
\text { velvety }\end{array}$ & $3 \mathrm{~F} 2$ & $3 \mathrm{D} 2$ & No & Natural \\
\hline DM0177 & 44 & 1B1 & $3 \mathrm{E} 2$ & Yes & $\begin{array}{l}\text { Dense, } \\
\text { velvety }\end{array}$ & $3 \mathrm{~F} 3$ & $3 F 3$ & No & $\begin{array}{c}\text { Mild reddish } \\
\text { pigment }\end{array}$ \\
\hline DM0192 & 44 & 1B1 & 1B1 & Yes & $\begin{array}{l}\text { Dense, } \\
\text { velvety }\end{array}$ & $3 \mathrm{~F} 2$ & 1B1 & Yes & $\begin{array}{c}\text { Mild reddish } \\
\text { pigment }\end{array}$ \\
\hline
\end{tabular}




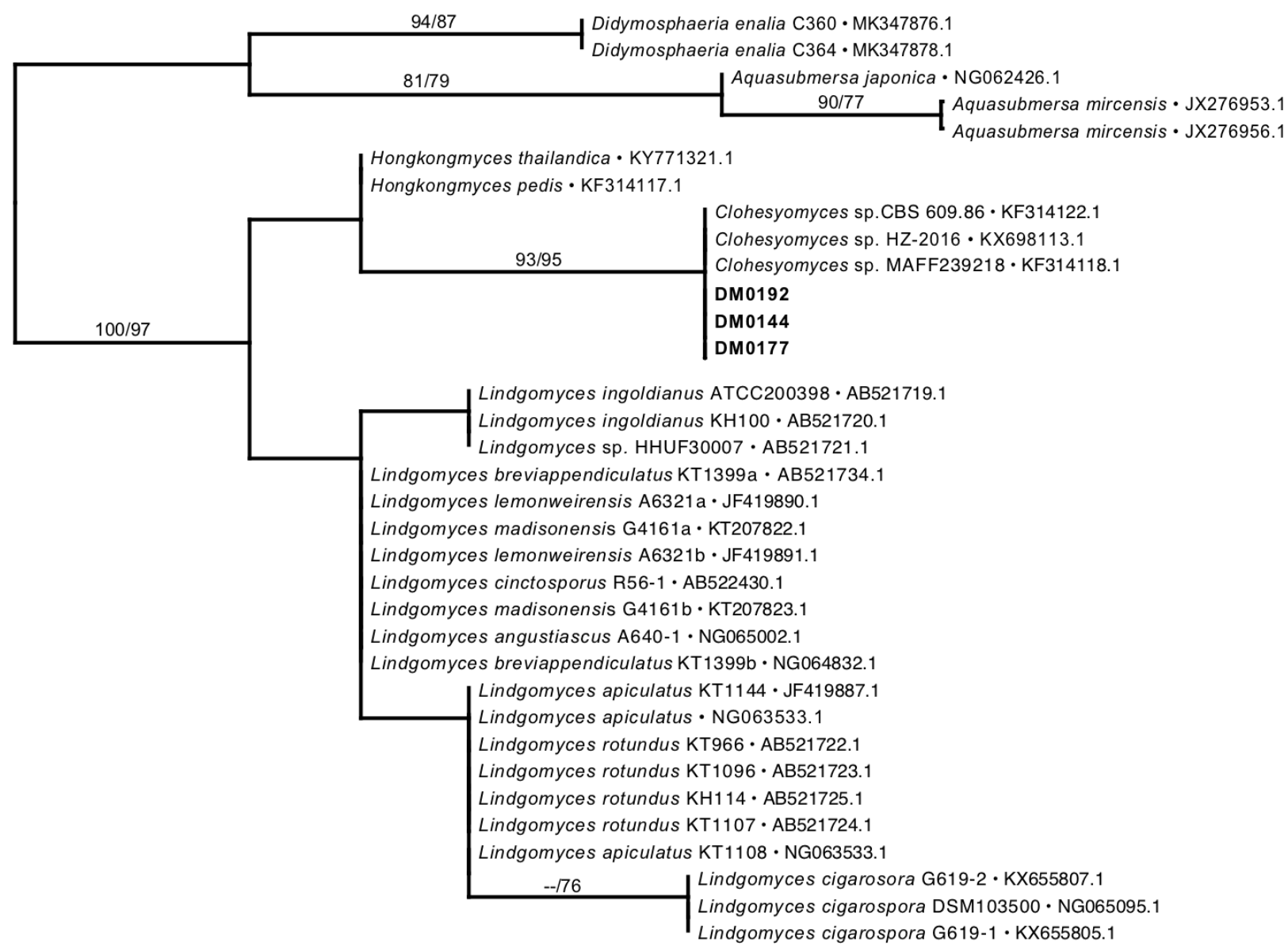

Figure 1. Maximum likelihood analysis of SSU rDNA data places the focal clade in Lindgomycetaceae. Bootstrap values $\geq 70$ are shown (maximum parsimony/maximum likelihood). Representative sequences were chosen for each genus. The final alignment consisted of 869 characters, of which 16 were variable and parsimony-informative.

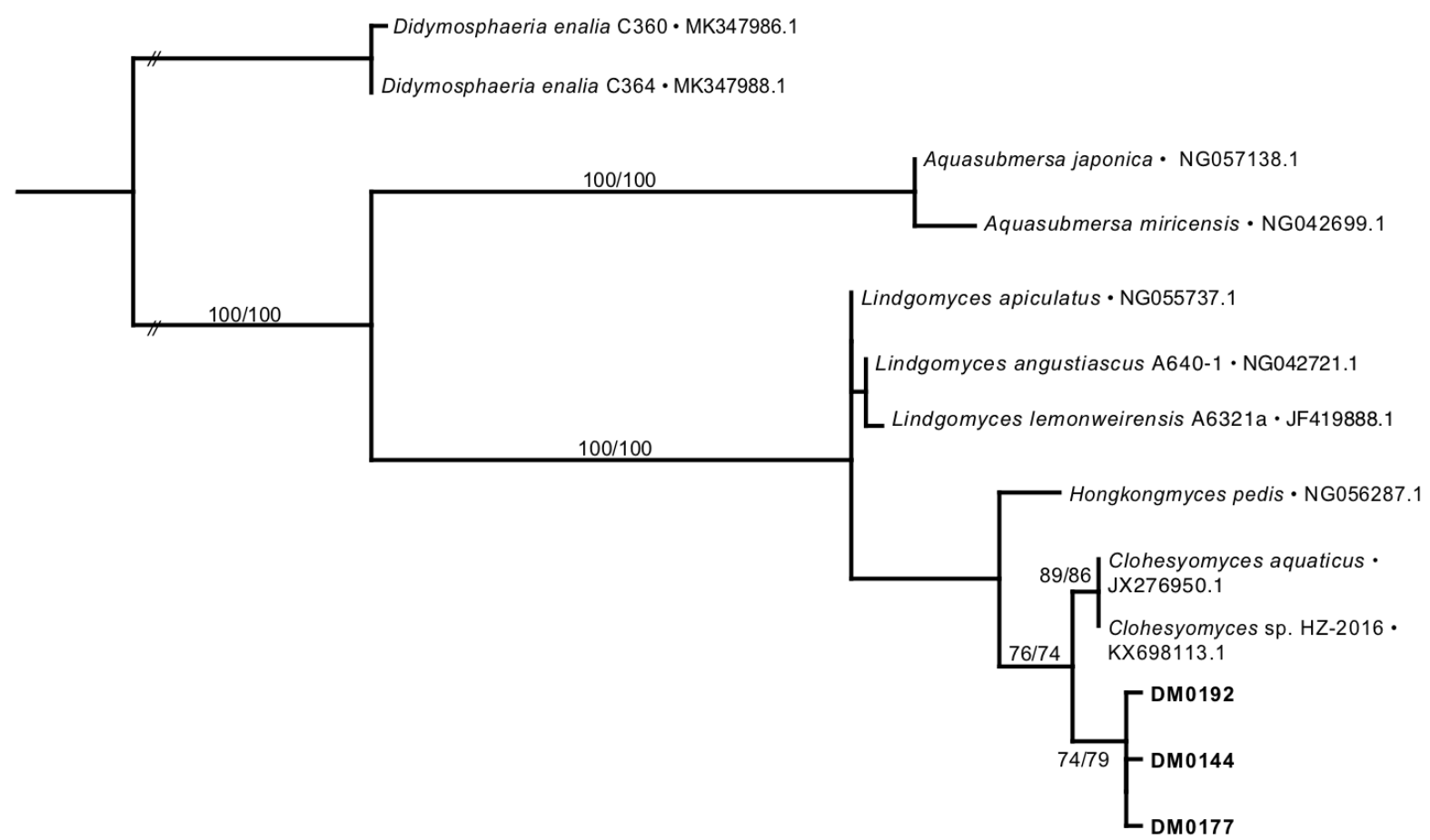

Figure 2. Maximum likelihood analysis of LSU rDNA data supports placement of the focal clade in Lindgomycetaceae. Bootstrap values $\geq 70$ are shown (maximum parsimony/maximum likelihood). The final alignment consisted of 836 characters, of which 75 were variable and 70 were parsimony-informative. 


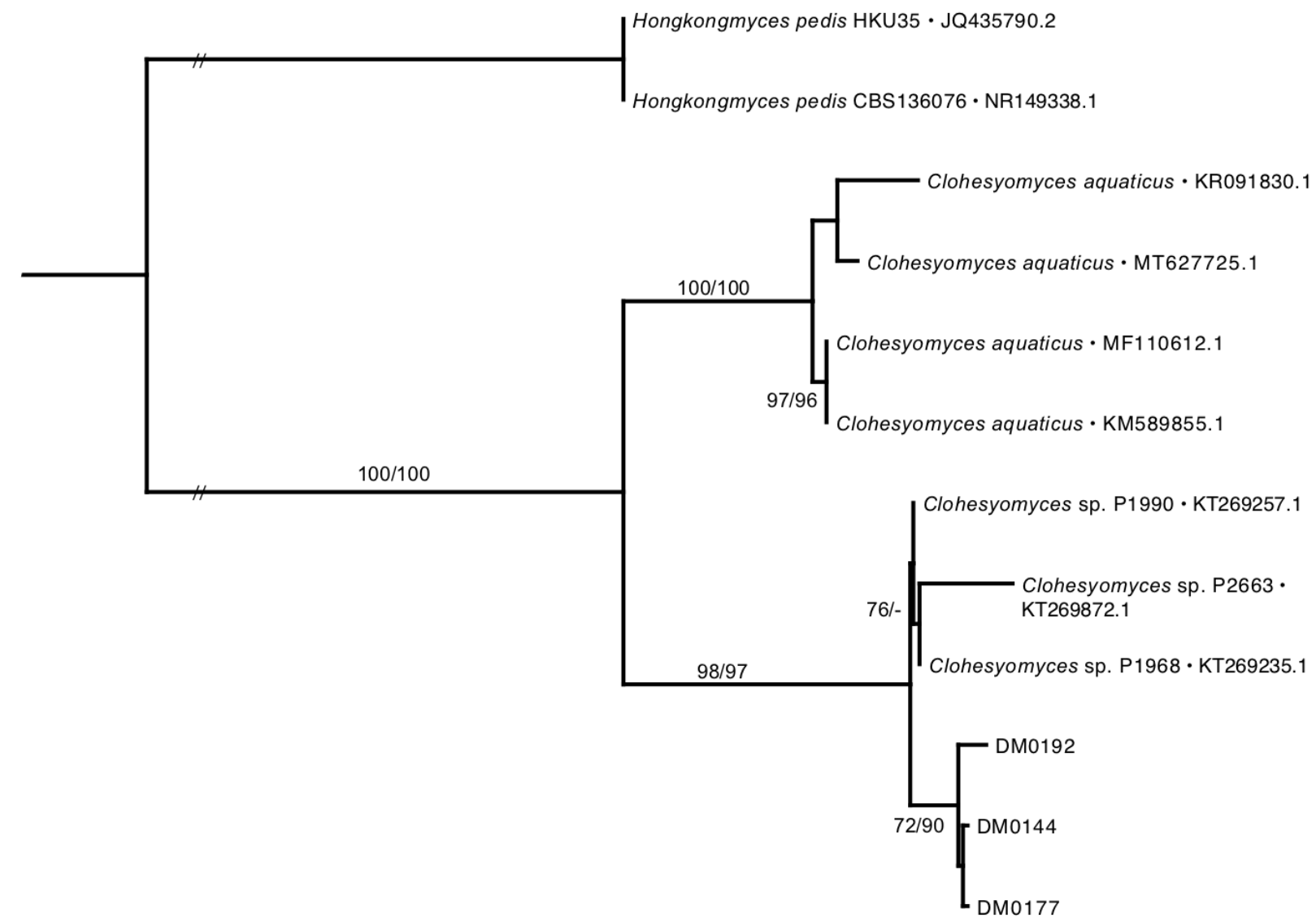

Figure 3. Maximum likelihood analysis of ITS rDNA data places the focal clade in Clohesyomyces and supports the description of C. symbioticus sp. nov. Bootstrap values $\geq 70$ are shown (maximum parsimony/maximum likelihood). The final alignment consisted of 591 characters, of which 134 were variable and 120 were parsimony-informative.

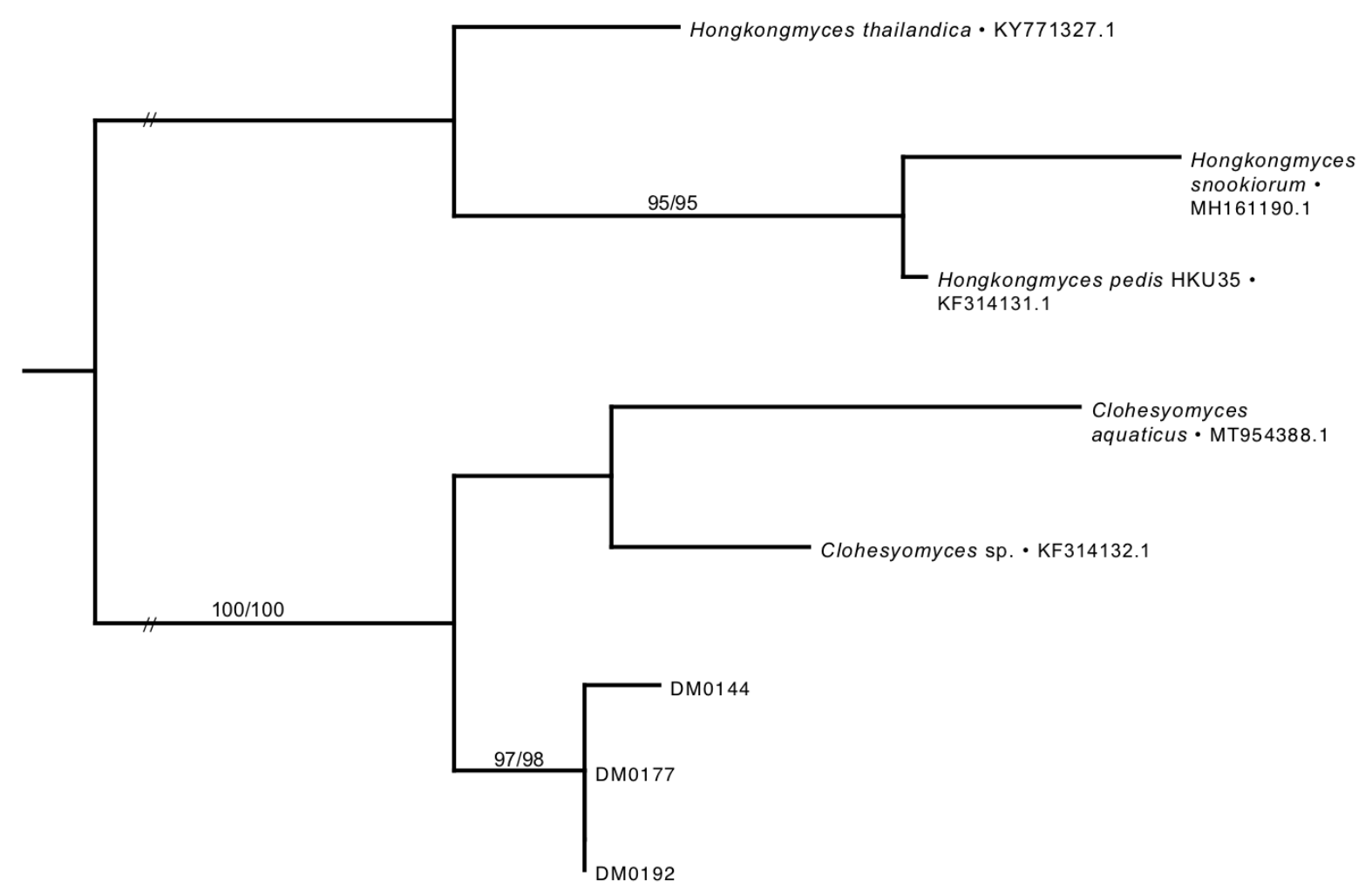

Figure 4. Maximum likelihood analysis of TEF-1a data places the focal clade in Clohesyomyces and supports the description of C. symbioticus. Bootstrap values $\geq 70$ are shown (maximum parsimony/maximum likelihood). The final alignment consisted of 454 characters, of which 55 were variable and 33 were parsimony-informative. 

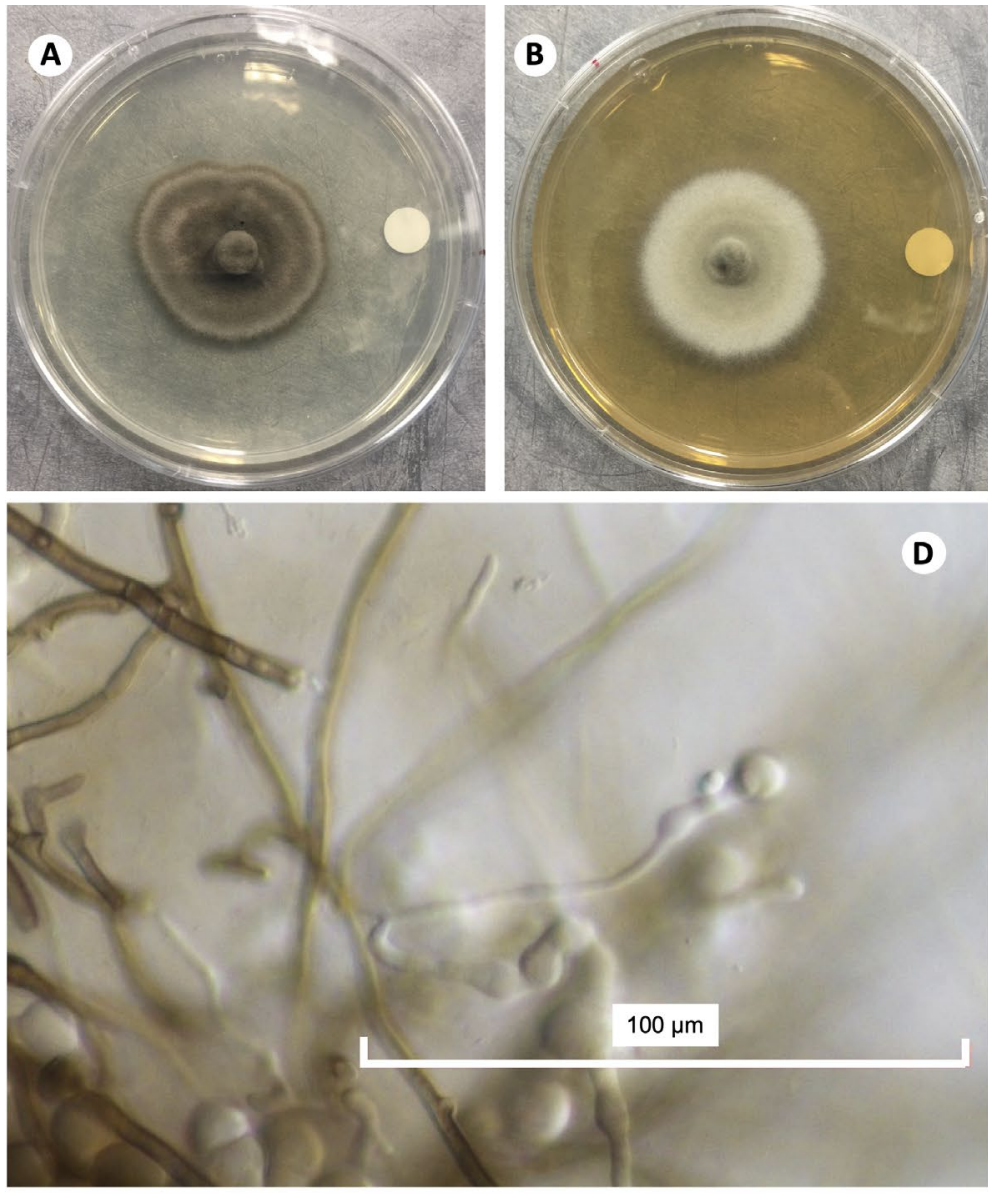

D

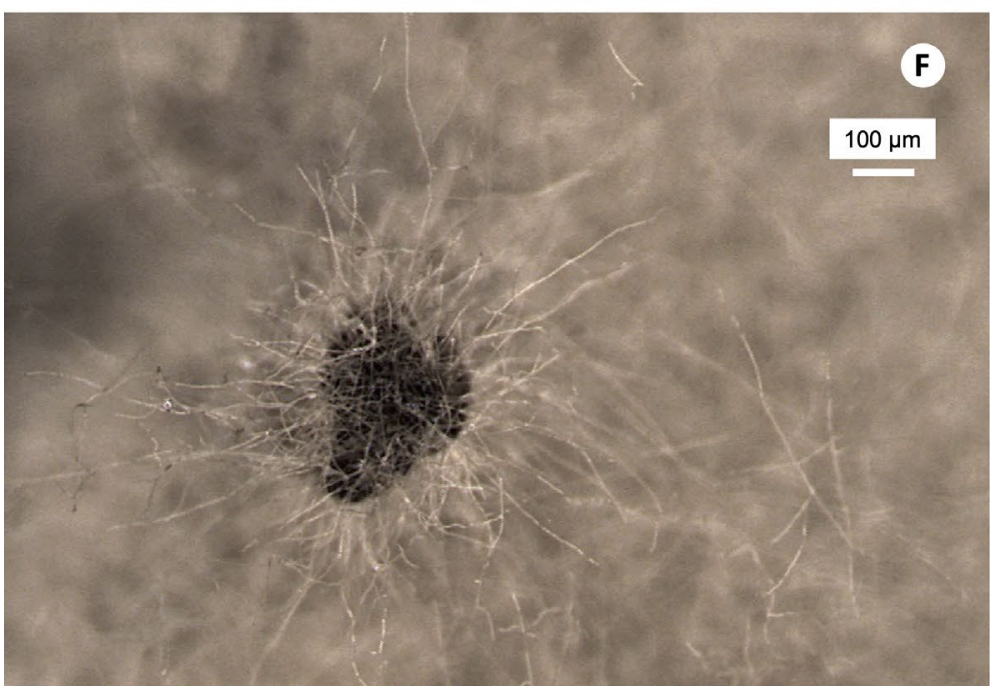

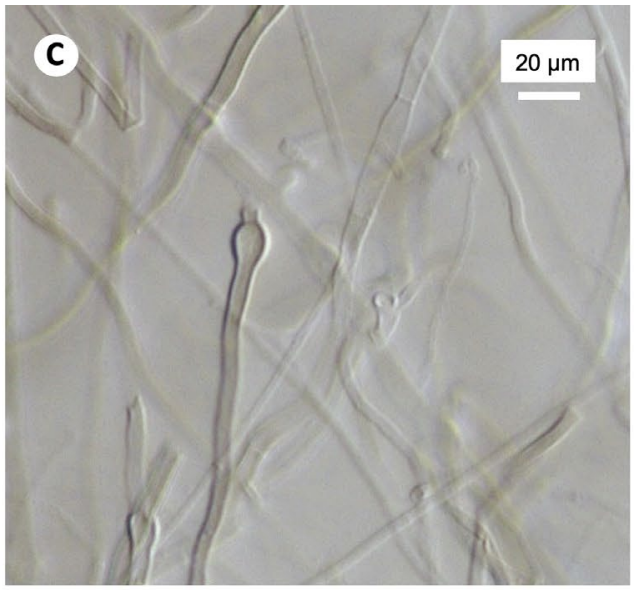
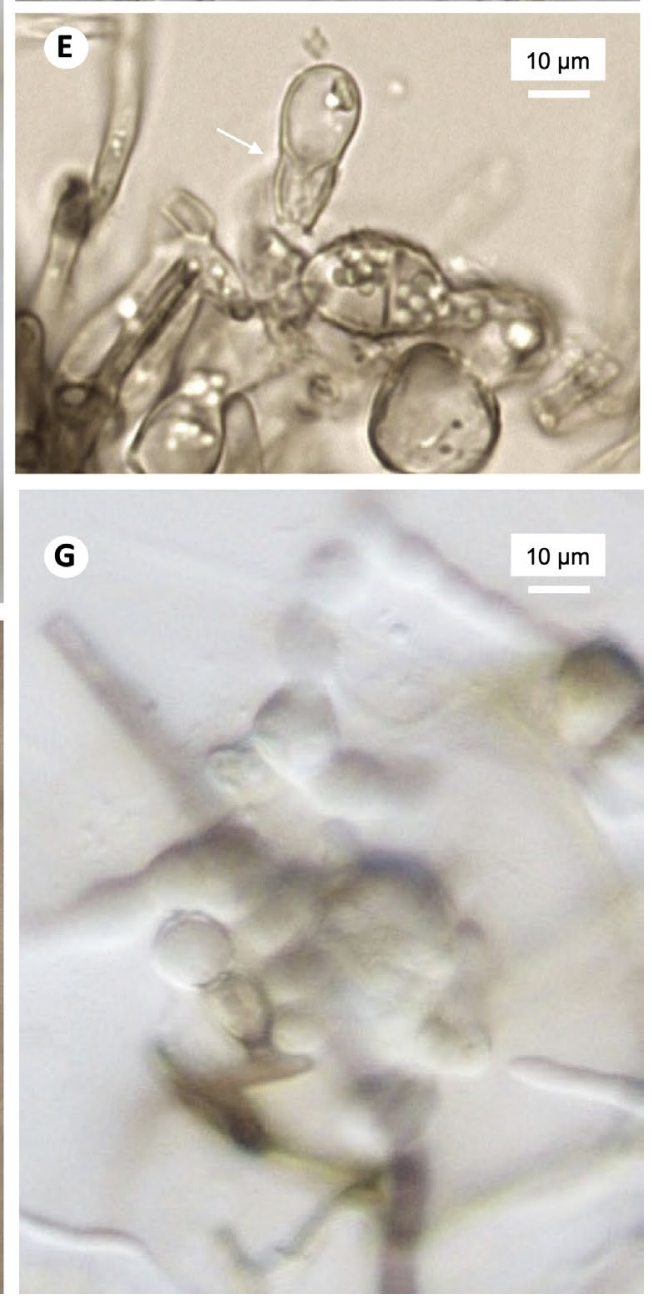

Figure 5. Morphology of Clohesyomyces symbioticus, illustrated by the type, ARIZ-AEADM0144. A - Isolate on 2\% MEA (100 mm plate); B - Isolate on PDA (100 mm plate). White circles on A and B are for white balance calibration; C - Conidiogenous cell; D - Details of hyphae and conidiogenous cells; E - Conidia and conidiogenous cell, illustrating ephemeral collarette (arrow); F - Pycnidium, formed on water after in proximity to thrice-autoclaved pine needles; $\mathrm{G}$ - Details of conidia and conidiogenous cells, with a nearly mature euseptate conidium. Images $\mathrm{C}$, D, and G were captured on a Nikon Eclipse Ni; E was captured on a Leica DM4000b.

Colony diameter on water agar averaged $53 \mathrm{~mm}$, $57 \mathrm{~mm}$, and $69 \mathrm{~mm}$ in $14 \mathrm{~d}$ for DM0144, DM0177, and DM0192, respectively. Diameter on cellulase medium averaged $\sim 33 \mathrm{~mm}$ in $14 \mathrm{~d}$ (DM0144, DM0177) and $42 \mathrm{~mm}$ (DM0192). On ligninase medium, colony diameters ranged from $38 \mathrm{~mm}$ in $14 \mathrm{~d}$ (DM0177, DM0144) to $47 \mathrm{~mm}$ (DM0192). No cellulase or ligninase activity was observed.

\section{Taxonomy}

Clohesyomyces symbioticus A. E. Arnold and D. C. Sandberg, sp. nov.

\section{MycoBank MB 841143}

Type: USA, Arizona, Yavapai County, Prescott, Willow Creek Reservoir (Willow Lake), endophytic in roots of healthy Persicaria amphibia (Polygonaceae) growing in standing water (16.8 and $20.4 \mathrm{~cm}$ depth at the time of collection), collected in 

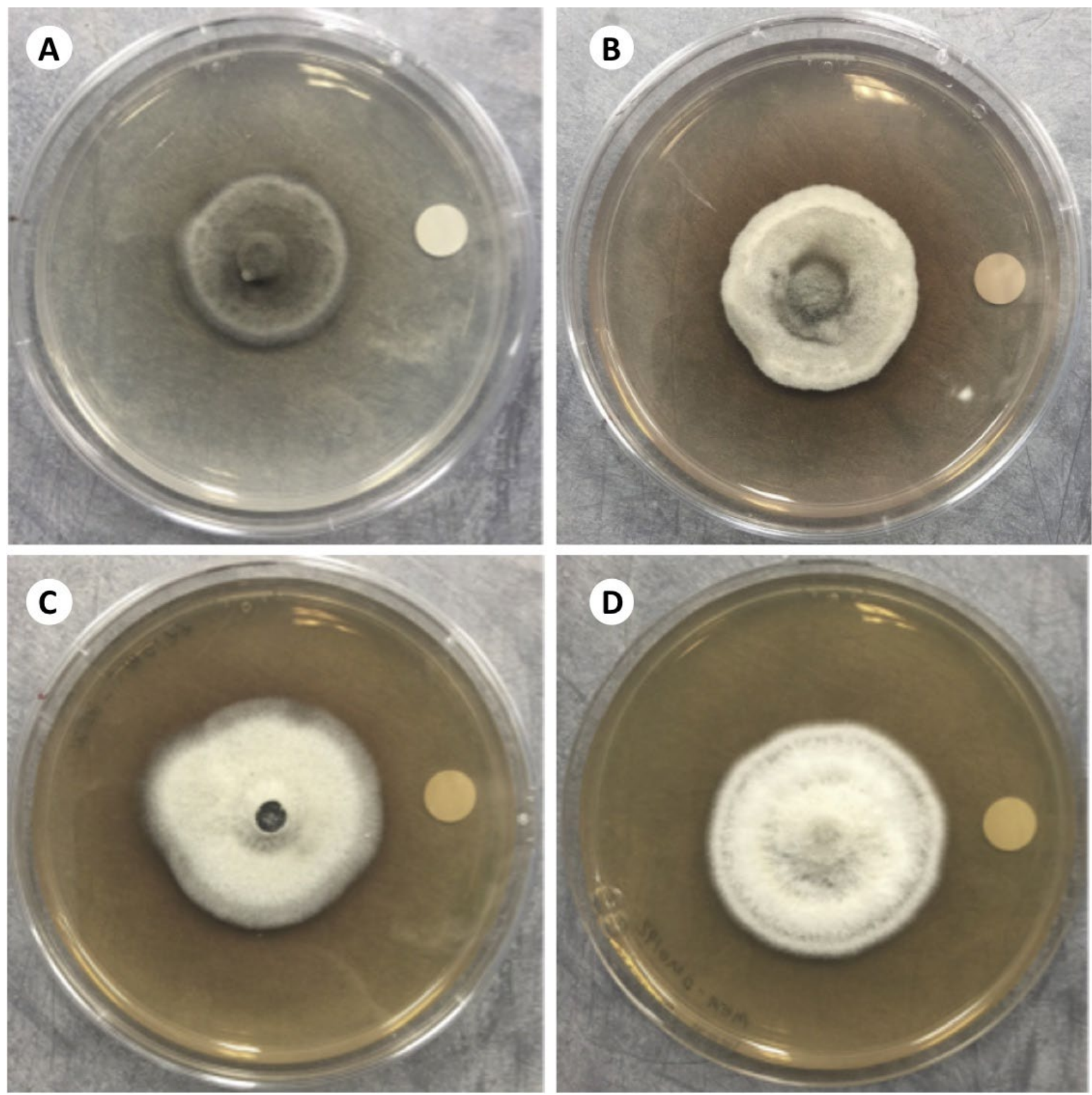

Figure 6. Colony morphology of paratypes of Clohesyomyces symbioticus (all on $100 \mathrm{~mm}$ plates): A - DM0177 on 2\% MEA; B - DM0192 on 2\% MEA; C - DM0177 on PDA; D - DM0192 on PDA. White dots on the undersides of plates are for white balance. Red pigment is visible in all plates, especially panels B and C.

June 2012, isolated by D. C. Sandberg (ARIZ-AEADM0144 - holotype; preserved in a metabolically inactive state (lyophilized) at the Robert L. Gilbertson Mycological Herbarium, University of Arizona).

Description. Colonies on PDA attained a diameter of $44 \mathrm{~mm}$ in $14 \mathrm{~d}$ at $22^{\circ} \mathrm{C}$, with a largely pale grey (1B1) to greyish white appearance from above, with dense and velvety aerial hyphae and rings of hyphal growth visible in some cultures; from below, typically olive grey (3F2) to goose turd (per Kornerup and Wanschen 1967, 3F3) at the colony center, and pale grey (1B1) to yellowish grey (3D2) to goose turd (3F3) from below. Margin variable. PDA remains colorless or may be colored red, either mild or dark, by a diffusible pigment that becomes more visible as colonies age past 1 month; not present in all subcultures. Colonies on 2\% MEA were similar in having a dense, velvety appearance, but they grew somewhat more slowly than on PDA (34-39 mm diameter in $14 \mathrm{~d}$ at $22^{\circ} \mathrm{C}$ ), with a generally darker grey aspect (from above, olive grey, 3E2) to grey (3B1), at times with a mildly yellowish grey aspect at the colony edge (3C2). From below, colonies on MEA were typically yellowish white (3F2) to olive $(3 \mathrm{~F} 3)$ at the center (but at times reddish brown, when red diffusible pigment was present); and at the edge, yellowish grey (3C2) to olive grey (3D2) to brownish grey (8C2, when red pigment was present). On MEA concentric growth rings were more visible than on PDA from above, but they were not evident from below. Diffusible red pigment was observed on MEA, ranging from mild to dark, but sometimes absent, as on PDA. Cellulase and ligninase negative; moderate and colorless growth on water agar, cellulose medium, and indulin medium. Vegetative hyphae brown with age to hyaline at growing edge of colony; with microscopy, typically olivaceous with obvious septation. 
Pycnidia 150-310 $\mu \mathrm{m}$ long, 60-130 $\mu \mathrm{m}$ diam., subglobose to ellipsoidal, irregular, very dark brown to black, infrequent, appearing on the medium where cuts were made in hyphal transfers; semi-immersed, solitary, unilocular, with a wall approximately 10-20 $\mu \mathrm{m}$ thick, comprised of thick-walled cells. Conidiogenous cells 8.5-12.5 $\mu \mathrm{m}$ long, hyaline, and as described by Zhang et al. (2012) for $C$. aquaticus, with marginal periclinal thickening and a short collarette. Conidia blastic, measuring 10.0-18.5 $\times 10.5-20.0 \mu \mathrm{m}$, becoming clearly delimited by a single septa at maturity, circular to ovoid, hyaline, smooth, thinwalled. Sexual structures undetermined.

Etymology. Named for its occurrence within healthy roots of living plants.

Notes. Pycnidia and conidia of C. symbioticus are smaller than those described for C. aquaticus (per Hyde 1993: pycnidia, 247-390 $\mu \mathrm{m}$ long and $156-260 \mu \mathrm{m}$ in diameter; conidia, $21-31 \times 9.5-12 \mu \mathrm{m})$. The conidia of C. symbioticus also are generally more spherical at maturity than those of $C$. aquaticus. The reddish pigment produced by DM0192, and especially DM0177, was less commonly visible in subcultures of DM0144, appearing only periodically. Pycnidia were rarely produced by all strains. Clohesyomyces symbioticus was detected in roots of individuals in several different areas of shallow water at Willow Creek Reservoir, with subsequent review of the Gilbertson endophyte collection highlighting the occurrence of the species also in roots of P. amphibia in shallow water at Lower Lake Mary (Flagstaff, Coconino County, Arizona, USA).

Other specimens examined. USA. Willow Creek Reservoir (Willow Lake), Prescott, Yavapai County, Arizona, DM0192 and DM0177, as described in Sandberg et al. (2014).

Vouchers and data deposition. Lyophilized vouchers of the paratypes DM0192 and DM0177 are deposited in the publicly accessible culture collection of the Robert L. Gilbertson Mycological Herbarium at the University of Arizona (ARIZ; accession numbers match isolate numbers; see above for holotype information), with data available at MyCoPortal.org. Sequence data for SSU rDNA, LSU rDNA, ITS rDNA, and TEF- $1 a$ are deposited in GenBank (Table 4).

Table 4. GenBank accessions for molecular data generated for this study.

\begin{tabular}{lcccc}
\hline Isolate & SSU rDNA & LSU rDNA & ITS rDNA & TEF-1a \\
\hline DM0144 & OK139667 & OK135170 & OK139670 & OK094526 \\
DM0177 & OK139668 & OK135171 & OK139671 & OK094527 \\
DM0192 & OK139669 & OK135172 & OK139672 & OK094528 \\
\hline
\end{tabular}

\section{Discussion}

Clohesyomyces symbioticus was identified from multiple strains isolated as endophytes from healthy, submerged roots of water smartweed in impounded lentic waters in central Arizona. Clohesyomyces thus aligns with the observation of Shearer (1993) that Ascomycota occurring in freshwater systems generally fall into two functional groups based on their nutrition: saprophytes, consuming dead plant material, such as C. aquaticus; and endophytic parasites of living algae and macrophytes, such as C. symbioticus.

A subsequent review of the culture collection of endophytes at the Robert L. Gilbertson Mycological Herbarium revealed that $C$. symbioticus also was detected in roots of $P$. amphibia in a second reservoir in the same region (Lower Lake Mary, Flagstaff, Coconino County, Arizona, USA; depth at collection, $11.9 \mathrm{~cm})$. In both locations, water smartweed was found in shallow water where seasonal drought occasionally exposes the substrate to drying (see Arizona Department of Environmental Quality 2015). In extensive surveys of terrestrial plants in the same region (e.g., Lau et al. 2013; Massimo et al. 2015; Huang et al. 2018; Bowman \& Arnold 2021), we did not detect this species, suggesting that it may be specialized to aquatic or periodically flooded habitats. Surveys by Sandberg et al. (2014) in 2011 and 2012 detected C. symbioticus only rarely, and only in submerged tissues of plants from relatively shallow and seasonally dry areas.

Our analyses expand the scope of Clohesyomyces in terms of taxonomy, ecology, and geography. Clohesyomyces has long been considered a monotypic genus comprising the saprobic species C. aquaticus (Hyde 1993), presently known from freshwater in Thailand, China, and Australia (see Zhang et al. 2012). The addition of C. symbioticus in North America highlights an endophytic association with roots of a widespread aquatic plant. Our analyses also suggest the potential existence of a third species in Clohesyomyces (Fig. 3), which includes root-endophytic strains from Microthlaspi perfoliatum (perfoliate pennycress, Brassicaceae; now Noccaea perfoliata; Al-Shehbaz 2014) that were detected in Europe (e.g., Greece and Germany) (Macia-Vicente et al. 2020). Thus the capacity to live endophytically in association with roots, including in both aquatic and terrestrial environments, may be more important in the genus than was suspected previously.

The genera Lindgomyces and Hongkongmyces are closely related to Clohesyomyces. Both occur in the United States, with records in Pennsylvania, Wisconsin, Florida, and North Carolina. Thus, our study expands the range of the family to include the southwestern USA. We anticipate that further exploration of aquatic habitats globally, especially across the wide range of $P$. amphibia, would reveal additional Clohesyomyces strains. In future work, we will characterize the interaction of C. symbioticus with diverse plants under flooded and non-flooded conditions to evaluate the physiological tolerance and symbiotic contributions of this newly described species.

\section{Acknowledgments}

We thank Ming-Min Lee, Caroline Plecki, Jamison Carey, Cady Flohrschutz and Adam Leon for laboratory assistance, Alison Harrington for discussion of morphology, Patrik Inderbitzin for inspiring this study, and the College of Agriculture and Life Sciences and Indigo Agriculture for supporting aspects of this 
work. DCS was supported by a Pierson Fellowship in the School of Plant Sciences at the University of Arizona during the original collections referenced here, which were conducted as part of his Master's research in Plant Pathology.

\section{References}

Al-Shehbaz, I. A. 2014. A synopsis of the genus Noccaea (Coluteocarpeae, Brassicaceae). Harvard Papers in Botany 19: 25-51. https:// doi.org/10.3100/hpib.v19iss1.2014.n3

Arizona Department of Environmental Quality. 2015. Watson Lake TMDL: Total nitrogen, $\mathrm{DO}, \mathrm{pH}$, and total phosphorus targets. https://legacy.azdeq.gov/environ/water/assessment, accessed on September 07, 2021.

Arnold, A. E., Miadlikowska, J., Higgins, K. L., Sarvate, S. D., Gugger, P., Way, A., Hofstetter, V., Kauff, F. \& Lutzoni, F. 2009. A phylogenetic estimation of trophic transition networks for ascomycetous fungi: are lichens cradles of symbiotrophic fungal diversification? Systematic Biology 58: 283-297.

Bowman, E. A. \& Arnold, A. E. 2021. Drivers and implications of distance decay differ for ectomycorrhizal and foliar endophytic fungi across an anciently fragmented landscape. ISME J. https:// doi.org/10.1038/s41396-021-01006-9

Carbone, I. \& Kohn, L. M. 1999. A method for designing primer sets for speciation studies in filamentous ascomycetes. Mycologia 91: $553-556$.

Costea, M. 2012. Persicaria amphibia. In: Jepson Flora Project (eds) Jepson eFlora, https://ucjeps.berkeley.edu/eflora/eflora_display. php?tid=69778, accessed on September 07, 2021.

Duan, X., Xu, F., Qin, D., Gao, T., Shen, W., Zuo, S., Yu, B., Xu, J., Peng, Y. \& Dong, J. 2019. Diversity and bioactivities of fungal endophytes from Distylium chinense, a rare waterlogging tolerant plant endemic to the Three Gorges Reservoir. BMC Microbiology 19: e278. https://doi.org/10.1186/s12866-019-1634-0

Edgar, R. C. 2004. MUSCLE: multiple sequence alignment with high accuracy and high throughput. Nucleic Acids Research 32: 1792-1797.

Gardes, M. \& Bruns, T. D. 1993. ITS primers with enhanced specificity for basidiomycetes - application to the identification of mycorrhizae and rusts. Molecular Ecology 2: 113-118.

Gazis, R., Miadlikowska, J., Lutzoni, F., Arnold, A. E. \& Chaverri, P. 2012. Culture-based study of endophytes associated with rubber trees in Peru reveals a new class of Pezizomycotina: Xylonomycetes. Molecular Phylogenetics and Evolution 65: 294-304.

Harrington, A. H., Del Olmo-Ruiz, M., U’Ren, J. M., Garcia, K., Pignatta, D., Wespe, N., Sandberg, D. C., Huang, Y.-L., Hoffman, M. T. \& Arnold, A. E. 2019. Coniochata endophytica sp. nov., a foliar endophyte associated with healthy photosynthetic tissue of Platycladus orientalis (Cupressaceae). Plant and Fungal Systematics 64: 65-79.

Hirayama, K., Tanaka, K., Raja, H. A., Miller, A. N. \& Shearer, C. A. 2010. A molecular phylogenetic assessment of Massarina ingoldiana sensu lato. Mycologia 102: 729-746.

Hoffman, M. T. \& Arnold, A. E. 2010. Diverse bacteria inhabit living hyphae of phylogenetically diverse fungal endophytes. Applied and Environmental Microbiology 76: 4063-4075.

Hopple, J. S. Jr. \& Vilgalys, R. 1994. Phylogenetic relationship among coprinoid taxa and allies based on data from restriction site mapping of nuclear rDNA. Mycologia 86: 96-107.

Huang, Y.-L., Zimmerman, N. B. \& Arnold, A. E. 2018. Observation on the early establishment of foliar endophytic fungi in leaf discs and living leaves of a model woody angiosperm, Populus trichocarpa (Salicaceae). Journal of Fungi (Basel, Switzerland) 4: e58.

Hyde, K. D. 1993. Tropical Australian freshwater fungi VI. Tiarosporella paludosa and Clohesymomyces aquaticus gen. et sp. nov. (Coelomycetes). Australian Systematic Botany 6: 169-173.
Hyde, K. D., Gareth Jones, E. B., Liu, J. K., Ariyawansa, H., Boehm, E., Boonmee, S., Braun, U., Chomnunti, P., Crous, P. W., Dai, D. Q., Diederich, P., Dissanayake, A., Doilom, M., Doveri, F., Hongsanan, S., Jayawardena, R., Lawrey, J. D., Li, Y. M., Liu, Y. X., Lücking, R., Monkai, J., Muggia, L., Nelsen, M. P., Pang, K. L., Phookamsak, R., Senanayake, I. C., Shearer, C. A., Suetrong, S., Tanaka, K., Thambugala, K. M., Wijayawardene, N. N., Wikee, S., Wu, H. X., Zhang, Y., Aguirre-Hudson, B., Alias, S. A., Aptroot, A., Bahkali, A. H., Berezza, J. L., Bhat, D. J., Camporesi, E., Chukeatirote, E., Gueidan, C., Hawksworth, D. L., Hirayama, K., Hoog, S. de, Kang, J. C., Knudsen, K., Li, W. J., Li, X. H., Liu, Z. Y., Mapook, A., McKenzie, E. H. C., Miller, A. N., Mortimer, P. E., Phillips, A. J. L., Raja, H. A., Scheuer, C., Schumm, F., Taylor, J. E., Tian, Q., Tibpromma, S., Wanasinghe, D. N., Wang, Y., Xu, J. C., Yacharoen, S., Yan, J. Y. \& Zhang, M. 2013. Families of Dothideomycetes. Fungal Diversity 63: 1-313.

Kohout, P., Sýkorová, Z., Ctvrtlíková, M., Rydlová, J., Suda, J., Vohník, M. \& Sudová, R. 2012. Surprising spectra of root-associated fungi in submerged aquatic plants. FEMS Microbiology Ecology 80: 216-235.

Kornerup, A. \& Wanscher, J. H. 1967. Methuen Handbook of Color. Methuen and Co., London.

Lau, M. K., Arnold, A. E. \& Johnson, N. C. 2013. Factors influencing communities of foliar fungal endophytes in riparian woody plants. Fungal Ecology 6: 365-378.

Liu, Y. J., Whelen, S. \& Hall, B. D. 1999. Phylogenetic relationships among ascomycetes: evidence from an RNA polymerase II subunit. Molecular Biology and Evolution 16: 1799-1808.

Maciá-Vicente, J. G., Piepenbring, M. \& Koukol, O. 2020. Brassicaceous roots as an unexpected diversity hot-spot of helotialean endophytes. IMA Fungus 11: 16. https://doi.org/10.1186/s43008-020-00036-w

Massimo, N. C., Nandi Devan, M. M., Arendt, K. R., Wilch, M. H., Riddle, J. M., Furr, S. H., Steen, C., U'Ren, J. M., Sandberg, D. C. $\&$ Arnold, A. E. 2015. Fungal endophytes in aboveground tissues of desert plants: infrequent in culture, but highly diverse and distinctive symbionts. Microbial Ecology 70: 61-76.

Mitchell, R. S. 1968. Variation in the Polygonum amphibium complex and its taxonomic significance. University of California Publications in Botany 45: 1-65.

Moora, M., Öpik, M., Davison, J., Jairus, T., Vasar, M., Zobel, M. \& Eckstein, R. L. 2016. AM fungal communities inhabiting the roots of submerged aquatic plant Lobelia dortmanna are diverse and include a high proportion of novel taxa. Mycorrhiza 26: 735-745.

Partridge, J. W. 2001. Persicaria amphibia (L.) Gray (Polygonum amphibium L.). Journal of Ecology 89: 487-501.

Raudabaugh, D. B., Iturriaga, T. \& Miller, A. N. 2018. Hongkongmyces snookiorum Raudabaugh, Iturr., \& A. N. Mill., sp. nov. Fungal planet description sheets: 716-784. Persoonia 40: 288-289.

Raja, H. A., Tanaka, K., Hirayama, K., Miller, A. N. \& Shearer, C. A. 2011. Freshwater ascomycetes: two new species of Lindgomyces (Lindgomycetaceae, Pleosporales, Dothideomycetes) from Japan and USA. Mycologia 103: 1421-1432. https://doi.org/10.3852/11077

Raja, H. A., Oberlies, N. H., El-Elimat, T., Miller, A. N., Zelski, S. E. \& Shearer, C. A. 2013. Lindgomyces angustiascus (Lindgomycetaceae, Pleosporales, Dothideomycetes), a new lignicolous species from freshwater habitats in the USA. Mycoscience 54: 353-361. https://doi.org/10.1016/j.myc.2012.12.004

Raja, H. A., Paguigan, N. D. \& Oberlies, N. H. 2015. Lindgomyces madisonensis Raja \& Oberlies, sp. nov. Fungal planet description sheets: 371-399. Persoonia 35: 306-307.

Raja, H. A., Paguigan, N. D., Fournier, J. \& Oberlies, N. H. 2017. Additions to Lindgomyces (Lindgomycetaceae, Pleosporales, Dothideomycetes), including two new species occurring on submerged wood from North Carolina, USA, with notes on secondary metabolite profiles. Mycological Progress 16: 535-552.

Rehner, S. A. \& Buckley, E. 2005. A Beauveria phylogeny inferred from nuclear ITS and EF1-a sequences: evidence for cryptic 
diversification and links to Cordyceps teleomorphs. Mycologia 97: 84-98. https://doi.org/10.1080/15572536.2006.11832842

Rodriguez, R. J., White, J. F. Jr., Arnold, A. E. \& Redman, R. S. 2009. Fungal endophytes: diversity and functional roles. New Phytologist 182: 314-330. https://doi.org/10.1111/j.1469-8137.2009.02773.x

Sandberg, D. C., Battista, L. J. \& Arnold, A. E. 2014. Fungal endophytes of aquatic macrophytes: diverse host-generalists characterized by tissue preferences and geographic structure. Microbial Ecology 67: 735-747. https://doi.org/10.1007/s00248-013-0324-y

Shearer, C. A, 1993. The freshwater ascomycetes. Nova Hedwigia, 56: $1-33$.

Stevens, K. J., Twanabasu, B. R. \& Kandalepas, D. 2018. Symbioses: Assisting Plant Success in Aquatic Settings. In: Finlayson, C. M. et al. (eds) The Wetland Book. Springer, Dordrecht. https://doi. org/10.1007/978-90-481-9659-3_49

Swofford, D. L. 2003. PAUP*. Phylogenetic Analysis Using Parsimony ("and other methods). Version 4. Sinauer Associates, Sunderland, Massachusetts.

Tsang, C.-C., Chan, J. F. W., Trendell-Smith, N. J., Ngan, A. H. Y., Ling, I. W. H., Lau, S. K. P. \& Woo, P. C. Y. 2014. Subcutaneous phaeohyphomycosis in a patient with IgG4-related sclerosing disease caused by a novel ascomycete, Hongkongmyces pedis gen. et sp. nov.: first report of human infection associated with the family Lindgomycetaceae. Medical Mycology 52: 736-747. https://doi. org/10.1093/mmy/myu043
Vilgalys, R. \& Hester, M. 1990. Rapid genetic identification and mapping of enzymatically amplified ribosomal DNA from several Cryptococcus species. Journal of Bacteriology 172: 4238-4246.

White, T. J., Bruns, T. \& Taylor, J. 1990. Amplification and Direct Sequencing of Fungal Ribosomal RNA Genes for Phylogenetics. In: Innis, M. A., Gelfand, D. H., Sninsky, J. J. \& White, T. J., Eds, PCR Protocols. A Guide to Methods and Applications, Academic Press, San Diego, 315-322. https://doi.org/10.1016/B978-0-12372180-8.50042-1

You, Y. H., Park, J. M., Park, J. H. \& Kim, J. G. 2015. Diversity of endophytic fungi associated with the roots of four aquatic plants inhabiting two wetlands in Korea. Mycobiology 43: 231-238. https:// doi.org/10.5941/MYCO.2015.43.3.231

Zhang, H., Hyde, K. D., McKenzie, E. H. C., Bahkali, A. H. \& Zhou, D. 2012. Sequence data reveals phylogenetic affinities of Acrocalymma aquatica sp. nov., Aquasubmersa mircensis gen. et sp. nov. and Clohesyomyces aquaticus (freshwater coelomycetes). Cryptogamie, Mycologie 33: 333-346. https://doi.org/10.7872/crym.v33. iss3.2012.333

Zhang, Y., Zhang, X. D., Fournier, J., Chen, J. J. \& Hyde, K. D. 2014. Lindgomyces griseosporus, a new aquatic ascomycete from Europe, including new records. Mycoscience 55: 43-48. https://doi. org/10.1016/j.myc.2013.05.003

Zwickl, D. J. 2006. Genetic algorithm approaches for the phylogenetic analysis of large biological sequence datasets under the Maximum Likelihood Criterion (PhD thesis). University of Texas at Austin. 